\title{
The Equi-Signal Zone Radio Beacon and Air Navigation.
}

\author{
By Dr. R. L. Smith-Rose.
}

$\mathrm{T}$ HE application of directional wireless methods to assist aerial and marine navigation has been progressing steadily during the past few years. After passing a period of uncertainty as to its accuracy and reliability, the wireless directionfinder has established itself as a very useful aid to marine navigation. Many hundred ships of all nationalities are now fitted with direction-finders, and a large number of fixed beacon transmitting stations are now in operation in various parts of the world for the specific use of such direction-finding installations.

As an alternative means of obtaining wireless bearings, the rotating loop beacon developed in Great Britain by the Royal Air Force is now undergoing a full scale trial with the installation erected last year at Orfordness, Suffolk. The advantage possessed by this method of operation is that the whole of the directional part of the system is at the transmitting station on shore, and any ship fitted with a radio receiver can take bearings with the aid of a suitable watch or chronometer. From reports already received from various ships which have taken bearing observations upon the Orfordness rotating beacon, it appears that this method of obtaining bearings is likely to prove at least a very useful auxiliary to the wireless aids to marine navigation. A survey of the progress made of recent research on both the above methods of directional wireless and their application to marine navigation was given in a lecture before the Royal Institution, an abstract of which appears in NATURE for April 5 and 12.

In the search for a suitable means of applying directional wireless methods to aeroplanes, two points become of vital importance. The first is that any additional apparatus in the machine, such as a direction-finding installation, is objectionable from the point of view of the otherwise unnecessary weight which it entails. Secondly, the normal travelling speed of aircraft is so high that it is necessary that bearings should be obtainable as rapidly as possible. This factor seriously limits the utility of the rotating beacon method, since bearings on the system are only obtainable at half-minute intervals, during which the position of the machine may have changed by distances of the order of one mile. It is further desirable that the whole of the receiving and recording apparatus in the aeroplane should be as automatic as possible, in order to avoid the infliction of unnecessary duties upon the pilot or wireless operator.

To meet these objections of the ordinary methods of direction-finding, considerable attention has been devoted in the United States during the past six years to the development of a method of courseindicating by wireless, which was patented by O. Scheller in Germany in 1907. Scheller's patent covered essentially the use of a transmitting station which was provided with two equal directive aerial systems pointing in different directions. The trans- mitter was arranged to send alternately on each aerial two letters with complementary Morse characters, such as $A$ (dot dash) on one aerial and $N$ (dash dot) on the other. At a receiver situated anywhere on either of the bisectors of the angle between the aerials the two letters would be received at equal intensity and would form a continuous dash. If the receiver is moved to one side or the other of this direction, one letter would predominate and would indicate to the observer to which side the receiver was displaced. In this way the four directions of equal signal strength are well defined, and a ship or aeroplane keeping the two received signals of equal intensity would pursue a straight line course directed to or away from the transmitting station. During the War, attempts were made by E. Buchwald ${ }^{1}$ to apply this method to assist the navigation of aeroplanes towards the transmitting station, which for the purpose was constructed with two inverted $L$ zerials at an angle of $60^{\circ}$ to each other. Some erratic results were obtained at first, due to the effect of the orientation and inclination to the horizon of the trailing wire antenna employed on the aeroplane. It was also found that the finite conductivity of the earth influenced the reliability of the results obtained.

In a later communication, F. Kiebitz ${ }^{2}$ described further experiments made in the navigation of ships with this system of transmission. Difficulties were experienced due to a variation in the conductivity of the earth in the proximity of the transmitter, but it was ultimately found possible to obtain a sharply defined course along which the ship was navigated.

The system does not appear to have received further attention in Germany, but in 1924 a paper was published by F. H. Engel and F. W. Dunmore ${ }^{3}$ which showed that attention was being devoted to this method of directional wireless by the U.S. Bureau of Standards. Since that date, and particularly during the past two years, considerable research and development of the application of this beacon system in the United States has taken place. The work has been largely carried out at or with the assistance of the Bureau of Standards for the Aeronautics Branch of the Department of Commerce. The technical results of the work have been described in a series of papers published in the Proceedings of the Institute of Radio Engineers and the Bureau of Standards Journal of Research, and the success of the system is evidenced by the recent proposal to establish a chain of some fifty directive beacons along the chief air routes of the United States.

The American type of radio beacon applies what is essentially Scheller's principle of directive transmission to two coil antennæ crossed at an angle of $135^{\circ}$ to each other, the signals being transmitted alternately from each coil. The early type of beacon was supplied from a quenched spark transmitter, and distinctive Morse signals, such as $A$ and $N$, were sent from each of the two coils

No. 3168, VoL. 126] 


\title{
The Equi-Signal Zone Radio Beacon and Air Navigation.
}

\author{
By Dr. R. L. Smith-Rose.
}

$\mathrm{T}$ HE application of directional wireless methods to assist aerial and marine navigation has been progressing steadily during the past few years. After passing a period of uncertainty as to its accuracy and reliability, the wireless directionfinder has established itself as a very useful aid to marine navigation. Many hundred ships of all nationalities are now fitted with direction-finders, and a large number of fixed beacon transmitting stations are now in operation in various parts of the world for the specific use of such direction-finding installations.

As an alternative means of obtaining wireless bearings, the rotating loop beacon developed in Great Britain by the Royal Air Force is now undergoing a full scale trial with the installation erected last year at Orfordness, Suffolk. The advantage possessed by this method of operation is that the whole of the directional part of the system is at the transmitting station on shore, and any ship fitted with a radio receiver can take bearings with the aid of a suitable watch or chronometer. From reports already received from various ships which have taken bearing observations upon the Orfordness rotating beacon, it appears that this method of obtaining bearings is likely to prove at least a very useful auxiliary to the wireless aids to marine navigation. A survey of the progress made of recent research on both the above methods of directional wireless and their application to marine navigation was given in a lecture before the Royal Institution, an abstract of which appears in NATURE for April 5 and 12.

In the search for a suitable means of applying directional wireless methods to aeroplanes, two points become of vital importance. The first is that any additional apparatus in the machine, such as a direction-finding installation, is objectionable from the point of view of the otherwise unnecessary weight which it entails. Secondly, the normal travelling speed of aircraft is so high that it is necessary that bearings should be obtainable as rapidly as possible. This factor seriously limits the utility of the rotating beacon method, since bearings on the system are only obtainable at half-minute intervals, during which the position of the machine may have changed by distances of the order of one mile. It is further desirable that the whole of the receiving and recording apparatus in the aeroplane should be as automatic as possible, in order to avoid the infliction of unnecessary duties upon the pilot or wireless operator.

To meet these objections of the ordinary methods of direction-finding, considerable attention has been devoted in the United States during the past six years to the development of a method of courseindicating by wireless, which was patented by O. Scheller in Germany in 1907. Scheller's patent covered essentially the use of a transmitting station which was provided with two equal directive aerial systems pointing in different directions. The trans- mitter was arranged to send alternately on each aerial two letters with complementary Morse characters, such as $A$ (dot dash) on one aerial and $N$ (dash dot) on the other. At a receiver situated anywhere on either of the bisectors of the angle between the aerials the two letters would be received at equal intensity and would form a continuous dash. If the receiver is moved to one side or the other of this direction, one letter would predominate and would indicate to the observer to which side the receiver was displaced. In this way the four directions of equal signal strength are well defined, and a ship or aeroplane keeping the two received signals of equal intensity would pursue a straight line course directed to or away from the transmitting station. During the War, attempts were made by E. Buchwald ${ }^{1}$ to apply this method to assist the navigation of aeroplanes towards the transmitting station, which for the purpose was constructed with two inverted $L$ zerials at an angle of $60^{\circ}$ to each other. Some erratic results were obtained at first, due to the effect of the orientation and inclination to the horizon of the trailing wire antenna employed on the aeroplane. It was also found that the finite conductivity of the earth influenced the reliability of the results obtained.

In a later communication, F. Kiebitz ${ }^{2}$ described further experiments made in the navigation of ships with this system of transmission. Difficulties were experienced due to a variation in the conductivity of the earth in the proximity of the transmitter, but it was ultimately found possible to obtain a sharply defined course along which the ship was navigated.

The system does not appear to have received further attention in Germany, but in 1924 a paper was published by F. H. Engel and F. W. Dunmore ${ }^{3}$ which showed that attention was being devoted to this method of directional wireless by the U.S. Bureau of Standards. Since that date, and particularly during the past two years, considerable research and development of the application of this beacon system in the United States has taken place. The work has been largely carried out at or with the assistance of the Bureau of Standards for the Aeronautics Branch of the Department of Commerce. The technical results of the work have been described in a series of papers published in the Proceedings of the Institute of Radio Engineers and the Bureau of Standards Journal of Research, and the success of the system is evidenced by the recent proposal to establish a chain of some fifty directive beacons along the chief air routes of the United States.

The American type of radio beacon applies what is essentially Scheller's principle of directive transmission to two coil antennæ crossed at an angle of $135^{\circ}$ to each other, the signals being transmitted alternately from each coil. The early type of beacon was supplied from a quenched spark transmitter, and distinctive Morse signals, such as $A$ and $N$, were sent from each of the two coils

No. 3168, VoL. 126] 
beacons erected near the terminal points was found to be of great service. Over the central part of the course signals from both beacons could be heard, and it was estimated that at the distance of 1200 miles from Honolulu the width of the equi-signal zone was about eight miles, which indicates that the zone employed was unusually sharp (about $0 \cdot 4^{\circ}$ ).

Some experiments carried out at an altitude of 2000 feet and described by H. Pratt indicate that at night the radio beacon system may be subject to erratic shift of the beacon course when the distance of transmission exceeds some fifty miles. In general, the changes in direction observed were less than $25^{\circ}$, but they were considered sufficiently serious to make the further study of this phase of the subject an urgent necessity. Apparently the errors are much reduced in magnitude by the use of a vertical antenna in the aeroplane, but this does not effect a complete cure and there will possibly be a limited range, of the order of about a hundred miles, over which this type of beacon may be considered to give results of the highest accuracy.

According to a recent publication, ${ }^{8}$ the Airways Division of the U.S. Department of Commerce proposes to build fifty directive radio beacons of the aural signalling type in addition to the nine such stations already in operation. These beacons will all operate on a wave-length band 950 -1050 metres (285-315 kilocycles per second) allotted by international agreement to beacon stations, and will be located along the main air routes at distances apart not exceeding 200 miles. In addition, these routes will be equipped with the low power non-directional
' marker' beacons which will give an aural signal to the pilot for a period of one or two minutes as he is flying overhead. These ' marker' beacons serve to inform the pilot as to his exact position along the course, and also to give him any local weather reports or other information of importance to the navigation of aircraft along the route in question.

Simultaneously with the development of these beacons special receiving equipment has been developed for use on the aeroplane. These receivers are designed to be sufficiently sensitive to work from the $6 \mathrm{ft}$. vertical aerial standardised for the aeroplane, and to give sufficient output for use with either the aural or visual methods of indication. Attention has been devoted to reducing the weight of the whole receiving equipment to the absolute minimum. It is likely that in the near future all mail and passenger carrying aeroplanes in the United States of America will be equipped with such receivers in order to make use of the extensive scheme of beacons now being erected for the specific purpose of assisting the navigation of aircraft.

${ }^{1}$ E. Buchwald : “Scheller"s Wireless Route Indicator Applied to Aeroplanes". Jahrbuch. d. drahtl. Tel., vol. 15, pp. 114-122; 1920. 2 F. Kiebitz: "New Experiments with Scheller's Directional Transmitter". Ibid. pp. 299-310.

${ }^{3}$ F. H. Engel and F. W. Dunmore: "A Directive Type of Radio Beacon and its Application to Navigation ". Scientific Paners, Bureat of Standards, vol. $19, \mathrm{pp} .281-295 ; 1924$

4. H. Dellinger and H. Pratt': "Development of Radio Aids to Air Navigation". Proc. Inst. Radio Eng., vol. 16, pp. 890-920; 1928 5 J. H. Dellinger and H. Diamond: "Radio Developments Applied to Aircraft". Aeromautical Eng., pp. 57-66;1929.

B F. G. Kear and W. G. Jackson: "Applying the Radio Range to the Airways". Proc. Inst. Radio Eng., vol. 17, pp. 2268-2282 ; 1929. "C. C. Shangraw: "Radio Beacons for Transpacifle Flights". Proc. Inst. Radio Eng., vol. 16, pp. 1203-1235; 1928.

sadio News, April 1930, p. 906 .

\section{The Second World Power Conference at Berlin.}

$\mathrm{T}$ HE Second Plenary World Power Conference which was held at Berlin on June 16-26 was probably one of the most ambitious and one of the most elaborately staged international meetings of recent years, and it is difficult on that account to follow with accuracy the main lines of development which were traced throughout the discussions. In the first place, the weight of documentary material was very large. Prior to the opening of the Conference, about 390 papers submitted by 37 or 38 countries had actually been printed and were available for examination; but during the Conference itself a number of additional papers appeared, mostly from Germany and Austria, with the result that the official collection will probably be rather more than 430 . In addition to that, the principal scientific and technical associations in Germany and Austria, and, to some extent also, Russia, had prepared special monographs surveying the position in their respective territories. These monographs did not form an intrinsic part of the Conference, but they should be considered as an additional contribution to the information collected.

The delegates and members assembled at the various sessions totalled about 3900 , while the papers were divided into 34 main sections corresponding roughly to the main aspects of national and international power development. During each full day six of these sections came up for examination at six meetings and the average number of speakers lay between 20 and 25, with, in certain cases, more than 30 taking part in the discussions. In all, therefore, during the period of the Conference, more than 1000 actual contributions were made to the work of assessing and judg. ing the material submitted. These statistics are necessary to a comprehension of what might have been and what was actually achieved. In no case did discussion elicit any new information of value or record experiences which were not already described in the papers themselves, and, if one were able to bring the discussions into line with the actual documents, one would find considerable duplication and little real originality.

The importance of the Conference lay, therefore, not so much in any survey of the international power situation it attempted, as in the work of direct personal co-operation which took place unofficially before and after the Conference meetings. It also served to illustrate the reality of the industrial recovery which has taken place in Germany since 1924, since one important feature was the very extensive series of visits to German industrial works which was staged during and after the Conference. It is unnecessary to touch on this

No. 3168 , Vou. 126] 